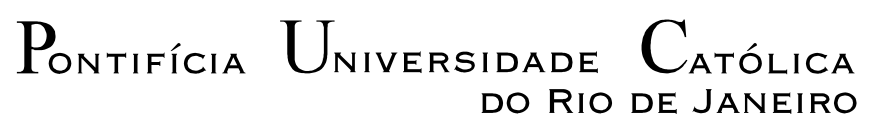

Maria da Gloria de Souza Almeida

\title{
A Importância da Literatura como Elemento de Construção do Imaginário da Criança com Deficiência Visual
}

Dissertação apresentada ao Programa de Pós-graduação em Letras da PUC-Rio como requisito parcial para obtenção do título de Mestre em Letras.

Orientadora: Profa. Eliana Lúcia Madureira Yunes Garcia 


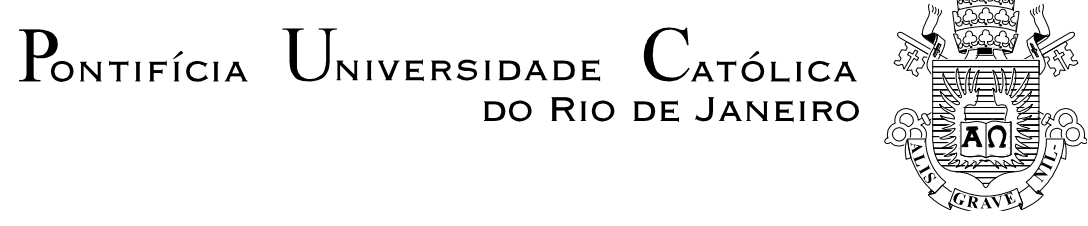

Maria da Glória de Souza Almeida

\section{A Importância da Literatura como Elemento de Construção do Imaginário da Criança com Deficiência Visual}

Dissertação apresentada como requisito parcial para obtenção do grau de Mestre pelo programa de PósGraduação em Letras do Departamento de Letras do Centro de Teologia e Ciências Humanas da PUC-Rio. Aprovada pela Comissão Examinadora abaixo assinada.

Profa. Eliana Lúcia Madureira Yunes Garcia
Orientadora
Departamento de Letras - PUC-Rio

Profa. Rosana Kohl Bines Departamento de Letras - PUC-Rio

Profa. Jackeline Lima Farbiarz Departamento de Artes \& Design - PUC-Rio

Profa. Valéria Cristina Ribeiro Pereira CES JF - Pesquisador Visitante

Profa. Denise Berruezo Portinari Coordenadora Setorial do Centro de Teologia e Ciências Humanas - PUC-Rio

Rio de Janeiro, 29 de setembro de 2011. 
Todos os direitos reservados. É proibida a reprodução total ou parcial do trabalho sem a autorização da universidade, da autora e do orientador.

Maria da Gloria de Souza Almeida

Graduou-se em Letras / Português e Literaturas e Espanhol em Literaturas pela Universidade Federal Fluminense - UFF. Especialização na Deficiência Visual pelo Instituto Benjamin Constant - IBC e Especialização em Alfabetização através do Sistema Braille pela Universidade Federal do Estado do Rio de Janeiro - UNIRIO. Atuação como Professora Regente nas Classes de Alfabetização, Língua Portuguesa e Cursos de Capacitação de Professores na área da Deficiência da Visão do IBC. É Chefe de Gabinete do Instituto Benjamin Constant.

Ficha Catalográfica

Almeida, Maria da Glória de Souza

A importância da literatura como elemento de construção do imaginário da criança com deficiência visual / Maria da Glória de Souza Almeida ; orientadora: Eliana Lúcia Madureira Yunes Garcia 2011.

207 f.; il. (color.) ; $30 \mathrm{~cm}$

Dissertação (mestrado)-Pontifícia Universidade Católica do Rio de Janeiro, Departamento de Letras, 2011.

Inclui bibliografia

1. Letras - Teses. 2. Literatura infantil. 3. Deficiência visual. 4. Imaginário. 5. Poder criativo. 6. Senso crítico. 7. Pensamento mágico. 7. Liberdade de expressão. 8. Mito. 9. Infância. I. Garcia, Eliana Lúcia Madureira Yunes. II. Pontifícia Universidade Católica do Rio de Janeiro. Departamento de Letras. III. Título.

CDD: 800 
Dedico este trabalho à Letícia, minha amada sobrinha neta que com seu espírito vivo e sensível, vivenciando a magia e o encanto dos seus sete anos, representa todas as crianças que ocuparam e ocupam minhas preocupações de educadora e se converteram no tema central deste estudo. 


\section{Agradecimentos}

\section{In memoriam}

À minha querida mãe, Mariazinha, agradeço o apoio, a confiança, o crédito que a mim foram conferidos por toda a trajetória de minha existência, sem limites ou reservas, buscando sempre aplainar minha estrada de pessoa cega.

Agradeço ao Departamento de Pósgraduação da Faculdade de Letras da Pontifícia Universidade Católica - PUC-Rio - Por abrir suas portas à diversidade e criar espaços para o alargamento das vias de uma verdadeira inclusão.

Agradeço a presteza e solicitude das funcionárias da Secretaria Francisca Ferreira de Oliveira (Chiquinha) e Daniele de Oliveira Cruz no atendimento de minhas dúvidas e necessidades.

Agradeço aos professores Rosana Khol, Marília Rothier, Pina Coco, Gilberto Mendonça Teles, Miguel Serpa Pereira e Maria Clara Luchetti Bingemer pelo respeito irretocável a mim dirigido, pela competência reconhecida que enriqueceram-me e a minha prática docente.

Agradeço as professoras Jacqueline Lima Farbiarz, Rosana Khol e Valéria Ribeiro Pereira pela gentileza em aceitarem o convite para integrarem a Banca Avaliadora da defesa de minha Dissertação e pelas imensuráveis contribuições que foram dadas ao meu trabalho.

Agradeço Eliana Yunes que se lançou ao desafio de assumir, sem reservas, a orientação de um trabalho que versava sobre assuntos fora do seu universo de pesquisas. Generosa e aberta, deu-me liberdade para expor ideias, trabalhar conceitos, trazer à luz minha experiência de educadora de crianças com deficiência visual e minha vivência de pessoa cega. 
Agradeço às minhas irmãs Isabel Maria e Maria de Lurdes, às minhas sobrinhas Ana Lúcia e Raquel, que estão permanentemente na retaguarda do meu cotidiano, dando-me a segurança e a tranqüilidade para que eu possa seguir adiante.

Agradeço aos meus queridos ledores, colaboradores anônimos e imprescindíveis: Helena, Marilia, Marcos e Tânia.

Agradeço aos meus companheiros da Direção Geral do Instituto Benjamin Constant: Érica, Maria Odete, Elcy, Valéria, Mônica e Sérgio que me dispensaram o incentivo necessário. 


\section{Resumo}

Almeida, Maria da Gloria de Souza; Garcia, Eliana Lúcia Madureira Yunes. A importância da literatura como elemento de construção do imaginário da criança com deficiência visual. Rio de Janeiro, 2011.207p. Dissertação de Mestrado - Departamento de Letras, Pontifícia Universidade Católica do Rio de Janeiro.

A importância da literatura como elemento de construção do imaginário da criança com deficiência visual é o tema do presente estudo. O texto literário, atuando como mediador desse processo de aquisição artisticocultural e do desenvolvimento do intelecto, mostra que é necessário buscar-se um rumo pedagógico para que crianças cegas ou com baixa visão tenham sua leitura de mundo enriquecida. A privação ou déficit severo da visão podem roubar da infância a capacidade de sonhar, de engendrar pensamentos mágicos, ricos de fantasia e beleza, tornando o imaginário da criança empobrecido e destituído de criatividade. Todavia, a imaginação, o poder criativo, o senso crítico, o extravasamento de emoções e sentimentos, pertencem a qualquer criança. A criança com deficiência visual é um ser cognoscente. Aprende, cria, recria. Porém, precisa vivenciar o mundo que a rodeia, experimentar tudo que a cerca. Sua sensibilidade e subjetivismo são desenvolvidos a partir de uma ação educativa aberta que supra suas demandas internas e premências cotidianas. Para tanto, a leitura sólida, prazerosa, instigadora é imprescindível. Propicia o avanço da criança em direção ao belo, à estética, à criação. O elemento imaginativo necessita entrar em estado de efervescência para fazer-se ativo e criador. A criança com deficiência visual pode alcançar tal evolução. Este trabalho mostrou possibilidades e fez o cotejo entre a criança vidente e a criança com deficiência visual, comprovando que a deficiência traz limites, mas não impõe impedimentos irreversíveis. O imaginário da criança cega ou com baixa visão constrói-se e alarga-se de acordo com as oportunidades que lhe são oferecidas.

\section{Palavras-chave}

Literatura infantil; deficiência visual; imaginário; poder criativo; senso crítico; pensamento mágico; liberdade de expressão; mito; infância. 


\section{Resúmen}

Almeida, Maria da Gloria de Souza; Garcia, Eliana Lúcia Madureira Yunes (Orientadora). La importância de la literatura como elemento de construcción del imaginario del niño con discapacidad visual. Rio de Janeiro, 2011. 207p. Disertación Maestrazgo - Departamento de Letras, Pontifícia Universidade Católica do Rio de Janeiro.

La importancia de la literatura como elemento de construcción del imaginario del niño con discapacidad visual es el tema del presente trabajo. El texto literario, actuando como mediador del proceso de aquisición del arte, de la cultura y del desarrollo del intelecto, muestra que es necesario buscarse un camino pedagógico para que niños ciegos y con visión reducida, tengan su lectura de mundo más rica. La privación o la discapacidad de la visión pueden robar de la infancia la capacidad de soñar y crear pensamientos mágicos, llenos de fantasía y belleza, haciendo el imaginario del niño pobre y sin creatividad. Aunque la imaginación, el poder creativo, la conciencia crítica, el transbordo de las emociones y sentimientos, que pertenecen a cualquier niño. El niño con discapacidad visual es un ser que se desarrolla. Aprende, cría y vuelve a crear. Precisa vivir y experimentar el mundo a su vuelta. Su sensibilidad y subjetivismo son desarrollados bajo una acción educativa abierta capaz de suprir sus demandas cotidianas infantiles. Para tanto, la lectura sólida, placentera, instigadora es imprecindible. Proporciona el avance del niño em dirección al bello, a la estética, a la criación. El elemento imaginativo necesita entrar en estado de efervecencia para hacerse activo y creador. El niño con discapacidad visual puede alcanzar tal evolución. Este trabajo mostró posibilidades y hizo el confronto entre el niño sin discapacidad visual y el niño ciego o con visión reducida, comprobando que la deficiencia trae límites, pero no impone impedimientos irreversibles. El imaginario del niño ciego o con discapacidad visual se construye y se amplia conforme las oportunidades que le son ofrecidas.

\section{Palabras llave}

Literatura infantil; discapacidad visual; imaginário; poder creativo; conciencia crítica; pensamiento mágico; libertad de expresión; mito; infancia. 


\section{Sumário}

CAPÍTULO I 13

CAPÍTULO II - Deficiência Visual e suas Implicações no Processo de Desenvolvimento Intelectual da Criança: Desvantagens e Possibilidades..... 30

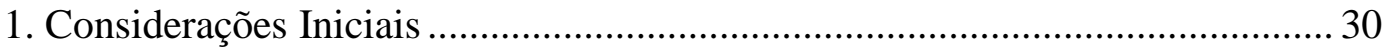

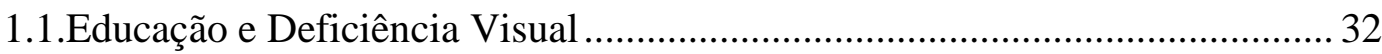

1.2.A Criança com Deficiência Visual Frente aos Desafios da Educação ............ 34

1.3.Deficiência Visual: Caracterização ................................................................. 35

2. Alfabetização - Uma Reflexão Necessária ...................................................... 42

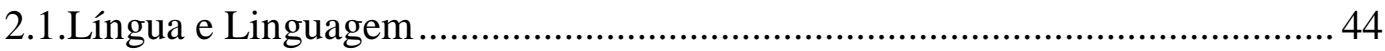

2.2.Implicações Pedagógicas à Luz da Teoria de Piaget....................................... 48

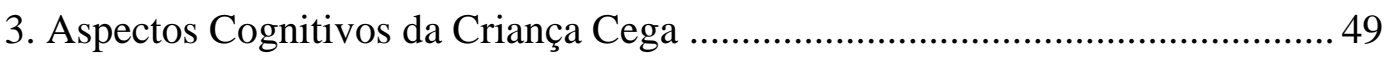

3.1.O Desenvolvimento Cognitivo da Criança Cega............................................ 51

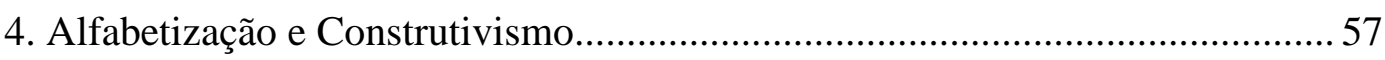

4.1.A Teoria e a Alfabetização da Criança Cega................................................... 60

4.2.Observações Nascidas Da Experiência Pessoal............................................... 65

CAPÍTULO III - Mitos e Símbolos na Magia da Linguagem da Infância ........... 70

1. A Literatura como Mediadora na Formação do Imaginário ............................... 70

1.1.O Texto Literário e a Criança ........................................................................... 72

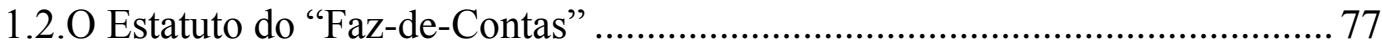

2. A Mágica da Infância na Magia da Literatura ................................................ 87

2.1.Os Elementos Mágicos no Desenvolvimento do Imaginário .......................... 89

2.2.A Importância dos Contos de Fadas no Período Letramento / Alfabetização 94

3. O Desenvolvimento do Imaginário da Criança com Deficiência Visual......... 102

CAPÍTULO IV - O Universo Interno Da Criança Com Deficiência Visual ...... 112

1.Realidade e Imaginação: Dois Mundos a Serem Explorados........................... 112

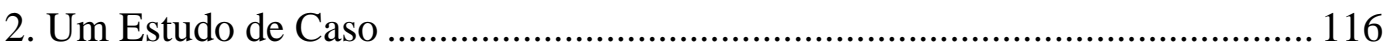




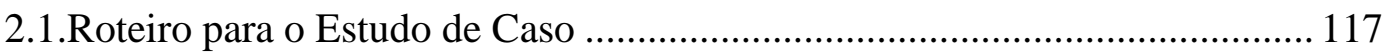

2.2.Perguntas para Provocar uma Conversa ..................................................... 120

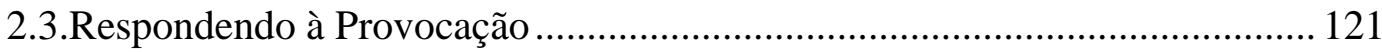

3. Pensando o Resultado da Entrevista................................................................. 124

3.1.Pensando o Desempenho das Crianças........................................................ 125

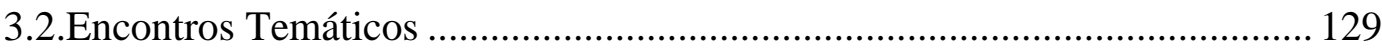

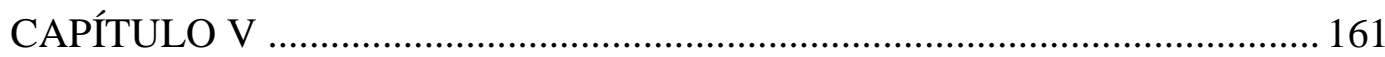

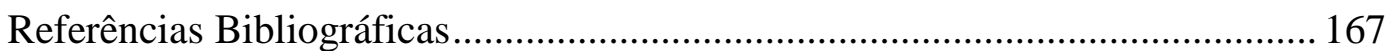

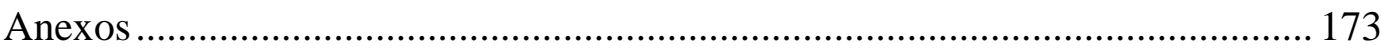

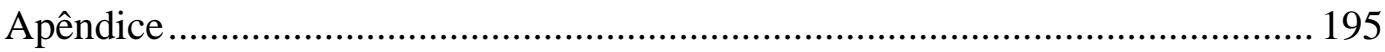




\section{Lista de Figuras}

Figura 1 - $1^{\circ}$ Encontro: A Magia dos Contos de Fadas 120

Figura 2 - $1^{\circ}$ Encontro: A Magia dos Contos de Fadas 120

Figura $3-1^{\circ}$ Encontro: A Magia dos Contos de Fadas 121

Figura $4-1^{\circ}$ Encontro: A Magia dos Contos de Fadas 121

Figura $5-1^{\circ}$ Encontro: A Magia dos Contos de Fadas 122

Figura 6 - $1^{\circ}$ Encontro: A Magia dos Contos de Fadas 122

Figura 7 - $1^{\circ}$ Encontro: A Magia dos Contos de Fadas 123

Figura $8-1^{\circ}$ Encontro: A Magia dos Contos de Fadas 123

Figura 9 - $2^{\circ}$ Encontro: A Tartaruga e a Lebre 124

Figura 10 - $2^{\circ}$ Encontro: A Tartaruga e a Lebre 125

Figura $11-2^{\circ}$ Encontro: A Tartaruga e a Lebre 125

Figura 12 - $2^{\circ}$ Encontro: A Tartaruga e a Lebre 126

Figura 13 - $2^{\circ}$ Encontro: A Tartaruga e a Lebre 126

Figura $14-2^{\circ}$ Encontro: A Tartaruga e a Lebre 127

Figura 15 - $2^{\circ}$ Encontro: A Tartaruga e a Lebre 127

Figura $16-3^{\circ}$ Encontro: O Circo 128

Figura $17-3^{\circ}$ Encontro: O Circo 129

Figura 18 - $3^{\circ}$ Encontro: O Circo 129

Figura $19-3^{\circ}$ Encontro: O Circo 130

Figura $20-3^{\circ}$ Encontro: O Circo 130

Figura $21-3^{\circ}$ Encontro: O Circo 131

Figura $22-3^{\circ}$ Encontro: O Circo 131

Figura $23-4^{\circ}$ Encontro: Falando de Poesia 133

Figura $24-4^{\circ}$ Encontro: Falando de Poesia 133

Figura $25-4^{\circ}$ Encontro: Falando de Poesia 134

Figura 26 - $4^{\circ}$ Encontro: Falando de Poesia 135

Figura $27-4^{\circ}$ Encontro: Falando de Poesia 135

Figura 28 - 5 Encontro: Criação de Texto com objetos concretos 137

Figura 29 - 5 Encontro: Criação de Texto com objetos concretos 137

Figura 30 - 5 Encontro: Criação de Texto com objetos concretos 138

Figura $31-5^{\circ}$ Encontro: Criação de Texto com objetos concretos 138

Figura 32 - $6^{\circ}$ Encontro: Criação de Texto sem objetos concretos 140 
" $O$ ato de ler não se esgota ao final da leitura do livro, nem das sensações que irrompem durante essa leitura. A leitura demora, permanece. Ela fica conosco, doendo ou alegrando-nos, e seu prazer não escoa rapidamente. A essa duração vamos chamar fruição, por conta de uma espécie de usufruto dos sentimentos e compreensões que irromperam na leitura. É como o sabor da fruta favorita que permanece como gosto bom na boca."

(Eliana Yunes) 